\title{
Minitrack Introduction - Knowledge management and entrepreneurship in early stage firms
}

\author{
Marianne Gloet \\ University of Melbourne \\ marianne.gloet@,unimelb.edu.au
}

Entrepreneurs and those building early stage firms have an additional challenge to those who are developing innovations in mature firms:

entrepreneurs are simultaneously trying to build their organizational systems and approach while also trying to develop their new products or services. Mature organizations often have established methods and systems in use to capture and manage knowledge that supports process improvement and product/ service innovation, whereas start-ups and early stage firms do not. This mini track sought studies of either early stage firms/ start-ups or mature firms, or both as comparisons, focusing on the knowledge and entrepreneurship challenges associated with different levels of firm maturity. We were particularly interested in studies that examine how firm maturity, size or other parameters are related to knowledge management and entrepreneurship approaches.

In the first paper, Entrepreneurial Organizations and the Use of Strategic Silence, the concept of strategic silence as a component of external communication strategy in entrepreneurial organizations is explored. Drawing on research about dynamic capabilities and external organizational communication, this study examines ways in which entrepreneurial organizations use silence as an effective communication strategy to reduce external uncertainty and to nurture growth during critical periods of development. Data were collected tracking the external communication of 54 entrepreneurial organizations that focus on mobile news application development. Results show a significant relationship between the attention organizations attract after product launch and an organization's performance. More specifically, the greater the magnitude of change from pre-launch to post-launch, from less frequent external communication to more frequent external communication, the more likely there is to be an increase in the product performance of an entrepreneurial organization. The findings highlight the role of strategic silence in entrepreneurial organizations in the early stages of development and

\author{
Danny Samson \\ University of Melbourne \\ d.samson@unimelb.edu.au
}

emphasize a more nuanced understanding of communication as an external tool.

The second article, Media Multiplexity in Entrepreneur-Mentor Relationships, examines how early stage entrepreneurs establish relationships with mentors through media multiplexity. Survey data were collected from high-tech entrepreneurs in the nascent business stage working in the New York City metropolitan area. Findings confirm that the use of multiple media in inter-organizational settings is important to entrepreneurship because multi-layered communication impacts resource acquisition. The findings regarding the antecedents of media multiplexity suggest that age similarity, ethnicity similarity, trust, and perceived value influence the adoption of media in a dyadic relationship. These findings help explain the motivations behind the use of multiple media in a resource-limited social context. 